\title{
Familial Multiple Lipomatosis: Case Report and Review of Literature
}

\author{
Mohammed Elakhiri", Mohamed Amine HANINE, Abdelfattah Aljalil, Youssef Darouassi
}

ENT and CFS Department, Avicenne Military Hospital, FMPM Cadi Ayad University - Marrakech - Morocco

DOI: $10.36348 /$ sjm.2020.v05i11.002

| Received: 18.10.2020 | Accepted: 04.11.2020 | Published: 13.11.2020

\section{*Corresponding Author: Mohammed Elakhiri}

\section{Abstract}

Familial multiple lipomatosis is a rare benign fatty tissue disease characterized by the presence of multiple lipomas. The diagnosis is clinically confirmed by ultrasound and computed tomography. The management is surgical. Some locations have aesthetic and psychological repercussions.

Key words: Lipoma - lipomatosis - Familial multiple lipomatosis.

Copyright ( $) 2020$ The Author(s): This is an open-access article distributed under the terms of the Creative Commons Attribution 4.0 International License (CC BY-NC 4.0) which permits unrestricted use, distribution, and reproduction in any medium for non-commercial use provided the original author and source are credited.

\section{CASe Report}

This is a 50-year-old patient with no pathological history, without alcohol or drugs use, who has similar cases in the family.

The patient reports from a young age multiple swelling in both upper and lower limbs (FIG) as well as in his trunk. The evolution of his nodules was marked by the gradual increase in size and number of these swellings, some of which, especially in the support areas, became sensitive without signs of infection.

2 years ago the patient reported the appearance of a swelling in the mastoid region, the ultrasound was in favor of a lipoma, and the additional assessment with the performance of a computed tomography (CT) of upper and lower limbs as well as thoracoabdominal CT scan confirmed the appearance of lipomas for the other swellings and showed the absence of mediastinal or peritoneal lipomas. The lab test results did not find any disturbance of lipid metabolism. The patient underwent a cervicotomy (Fig 5), the pathological examination showed the histological features of lipoma.

\section{Comment}

Lipomatosis is defined by the presence of multiple encapsulated lipomas that can grow in all fatty regions of the body. They are benign mesenchymal tumors of the adipose tissue of the hyopoderm, or subfascial adipose tissue.

Lipomatosis are genetic (autosomal dominant mesosomatic lipomatosis) or acquired (LaunoisBensaude lipomatosis, often associated with chronic alcoholism)
Familial multiple lipomatosis is one of the hereditary lipomatosis. it is a rare inherited disease of autosomal dominant inheritance, the frequency of which is unknown. It is defined by the presence of multiple lipomas encapsulated on the trunk and extremities, generally sparing the head and shoulders [1-2].

On gross examination, lipomas appear as a soft, yellowish, smooth, mobile, encapsulated mass and possibly with fine septa. Microscopically, lesions show lobular growth of mature adipocytes with demarcated limits, a fibrous capsule, and a central vacuole [3].

Generally the condition is more common in men between the ages of 40 and 60, although it can be seen at any age. The incidence is unknown, but the prevalence may be higher in Mediterranean people.

Clinically results in the form of several rounded to oval swellings, ranging from 2 to more than $15 \mathrm{~cm}$, well limited, painless sometimes sensitive, and mobile in both superficial and deep planes, predilection site is the trunk and limbs (Fig 1,2,3), generally sparing the head and shoulders [1-2] (Fig 4 ).

Paraclinical exploration is essentially based on ultrasound showing an elongated, well-defined, homogeneous subcutaneous mass of variable echogenicity depending on the degree of connective tissue [3-4-5].

Computed tomography reveals a globally homogeneous oval formation of negative density. MRI reveals a homogeneous signal mass with or without thin internal partitions, hyperintense in $\mathrm{T} 1$-weighted and 
hypo-intense in fat signal suppression techniques, without contrast enhancement after injection of gadolinium [3-6].

The outcome is marked by the gradual increase in size of the lipomas, without disturbances in lipid metabolism [1-2], malignant transformation has never been described. The treatment is surgical with aesthetic objective.

\section{CONCLUSION}

Familial multiple lipomatosis is a rare benign pathology, the diagnosis of which is mainly clinical confirmed by ultrasound, the therapeutic management is based on surgery. This disease sometimes presents a huge aesthetic problem with psychological repercussion.

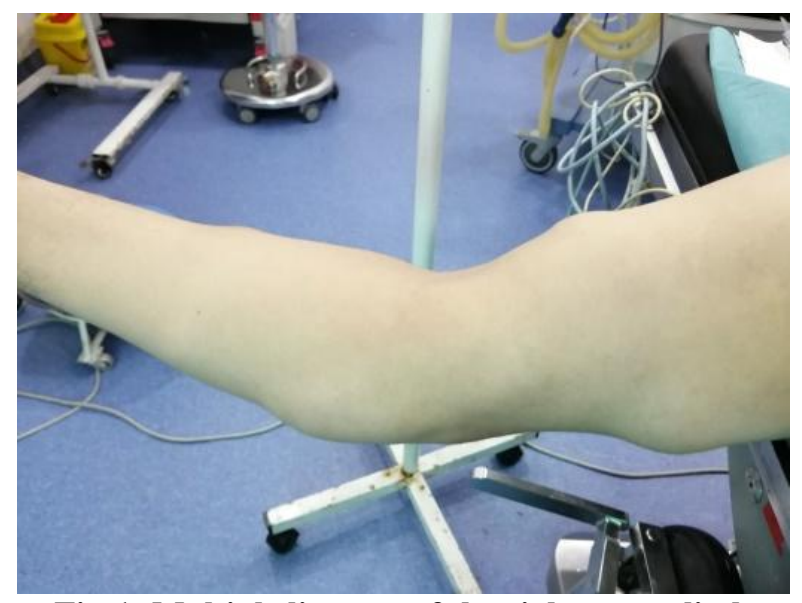

Fig-1: Multiple lipomas of the right upper limb

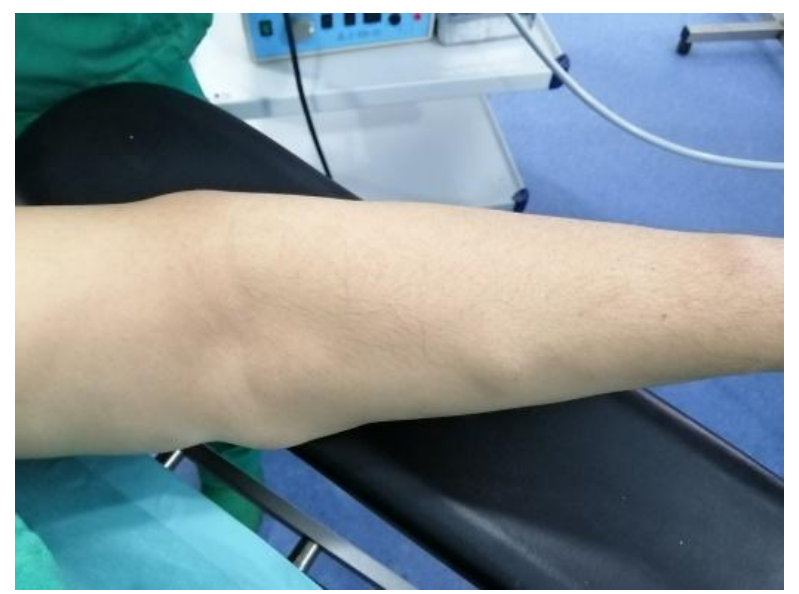

Fig-2: Multiple lipomas of the left upper limb

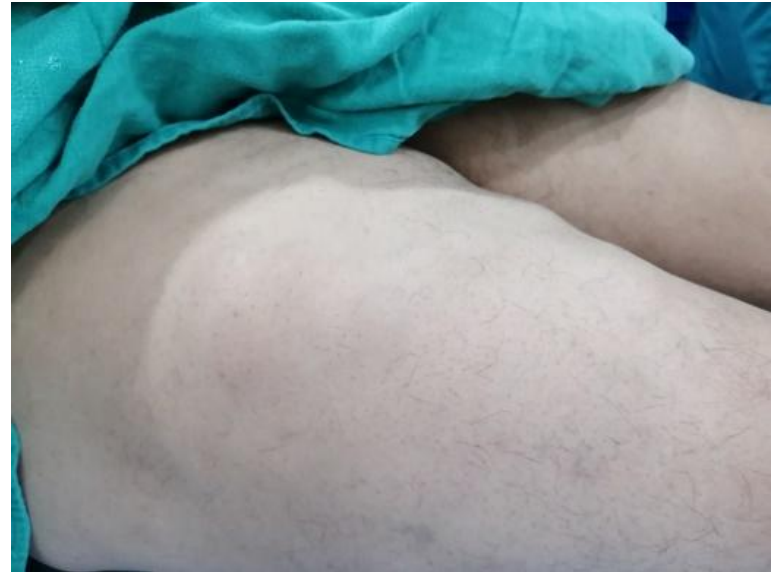

Fig-3: Multiple lipomas of the lower limb

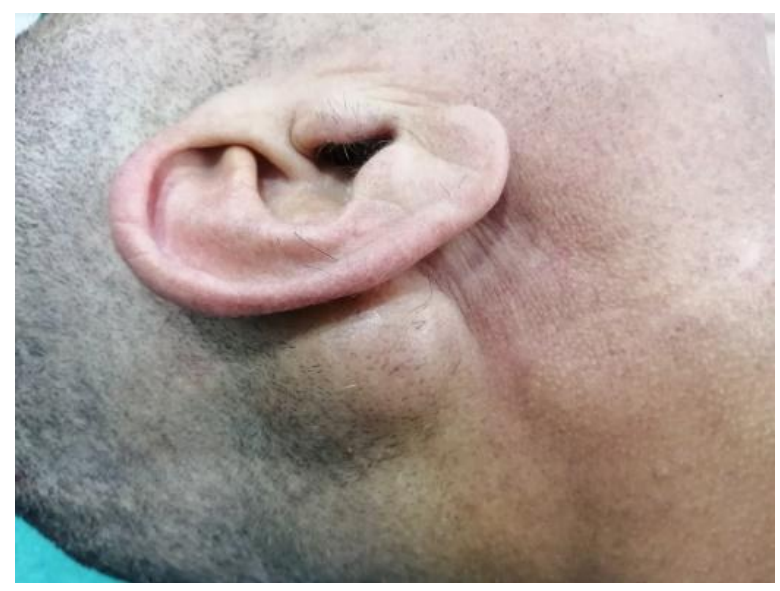

Fig-4: Lipoma of the mastoid region

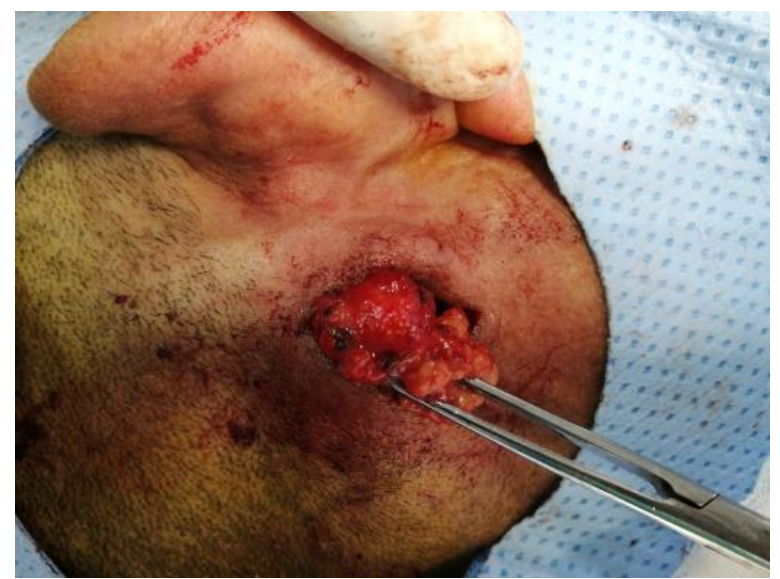

Fig-5: Intraoperative view

\section{REFERENCES}

1. Toy, B.R. (2003). Familial multiple lipomatosis. Dermatol Online J, 9:9.

2. Leffell, D.J., Braverman, I.M. (1986). Familial multiple lipomatosis. Report of a case and a review of the literature. JAmAcad Dermatol, 15:275-9.

3. Fuchs, A., Henrot, P., Walter, F., Iochum, S., Vignaud, J., Stines, J. (2002). Lipomatous tumors of soft tissues in the extremities and the waist in adults. J Radiol, 83:1035-57. 
4. Inampudi, P., Jacobson, J. A., Fessell, D. P., Carlos, R. C., Patel, S. V., Delaney-Sathy, L. O., \& van Holsbeeck, M. T. (2004). Soft-tissue lipomas: accuracy of sonography in diagnosis with pathologic correlation. Radiology, 233(3), 763-767.

5. Kuwano, Y., Ishizaki, K., Watanabe, R., \& Nanko, H. (2009). Efficacy of diagnostic ultrasonography of lipomas, epidermal cysts, and ganglions. Archives of dermatology, 145(7), 761764.

6. O'Sullivan, P., O'Dwyer, H., Flint, J., Munk, P. L., $\&$ Muller, N. (2007). Soft tissue tumours and masslike lesions of the chest wall: a pictorial review of $\mathrm{CT}$ and MR findings. The British Journal of Radiology, 80(955), 574-580. 